\title{
Vitamin D3/VDR resists diet-induced obesity by modulating UCP3 expression in muscles
}

\author{
Yue Fan ${ }^{1,5+}$, Kumi Futawaka ${ }^{1+}$, Rie Koyama ${ }^{1}$, Yuki Fukuda ${ }^{1}$, Misa Hayashi ${ }^{1}$, Miyuki Imamoto ${ }^{2}$, Takashi Miyawaki ${ }^{3}$,
} Masato Kasahara ${ }^{2}$, Tetsuya Tagami ${ }^{4}$ and Kenji Moriyama ${ }^{1,2,4^{*}}$

\begin{abstract}
Background: The impact of vitamin D3 (VD3) on obesity has been reported in the past. Our study was aimed at investigating the possible mechanisms by which VD3 affects obesity induced by a high fat diet.

Methods: Eight-week-old C57BL/6 J male mice were fed a normal- or high-fat diet for 9 weeks and were treated with a gavage of vehicle (corn oil) or cholecalciferol $(50 \mu \mathrm{g} / \mathrm{kg}$, daily). Body weight, white adipose tissue weight, blood lipid and glucose levels were measured. In addition, we investigated the expression of $1,25(\mathrm{OH})_{2} \mathrm{D}_{3}$ (calcitriol)NDR-regulated genes involved in energy and lipid metabolism, such as of uncoupling protein 3 (UCP3), by using qRT-PCR in the liver, adipose tissue, skeletal muscle and C2C12, L6, and H-EMC-SS cells. We also measured UCP3 promoter transcription in the same cell lines using a Dual Luciferase Assay. Furthermore, we analyzed the binding site consensus sequences of VDR on the UCP3 promoter.

Results: Mice consuming a high-fat diet treated with cholecalciferol had lower body weight and adipose tissue weight and higher expression of UCP3 compared to the other treatment groups. Changes in the expression of genes correlated with calcitrio/NDR. Luciferase activity was dose-dependently associated with calcitrio/NDR levels. We confirmed the functional VDR binding site consensus sequences at $-2200,-1561,-634$, and +314 bp in the UCP3 promoter region.
\end{abstract}

Conclusion: We suggest that VD3NDR inhibits weight gain by activating UCP3 in the muscles.

Keywords: VDRE, Transcription, Promoter

\section{Background}

Obesity is associated with vitamin D deficiency, and both are areas of active public health concern. Vitamin $\mathrm{D}$ $\left(1,25(\mathrm{OH})_{2} \mathrm{D}_{3}\right)$ is a steroid hormone that has a range of physiological functions in skeletal and nonskeletal tissues, and can contribute to prevent and/or treat several diseases. We hypothesize that increased UCP3 expression promotes mitochondria activity and fatty acid oxidation. We provide evidence that VD3/VDR regulates

\footnotetext{
* Correspondence: kemori@mukogawa-u.ac.jp

${ }^{\dagger}$ Equal contributors

'Department of Medicine \& Clinical Science, Faculty of Pharmaceutical Sciences, Mukogawa Women's University, Hyogo 663-8179, Japan

${ }^{2}$ Department of Nephrology and Blood Purification, Institute of Biomedical Research and Innovation, Kobe Medical Frontier Center, Kobe 650-0047, Japan

Full list of author information is available at the end of the article
}

body weight and white adipose tissues weight without changing food intake and blood lipid levels. We confirmed UCP3 gene transcription is initiated by $1,25(\mathrm{OH})_{2} \mathrm{D}_{3}$ (calcitriol)/VDR binding to the UCP3 promoter on the molecular basis, which reinforces energy metabolism, resulting in resistance to obesity caused by a high fat diet, as dealt with in this paper.

\section{Introduction}

Obesity, most commonly caused by excessive dietary calories due to a high-fat diet, is increasing in prevalence worldwide [1]. Obesity is associated with several chronic diseases, including fatty liver, heart disease, type 2 diabetes mellitus, certain types of cancer, and osteoarthritis $[2,3]$. The balance between energy intake and energy utilization maintains body weight. Energy is obtained by 
consuming calories and can be stored in adipose tissues or can be utilized by the body to sustain basic cellular functions and physical activities [4]. Since energy homeostasis is maintained by signals from feedback loops that regulate food intake, energy expenditure, lipid metabolism, and glucose metabolism [5], variation in the genes involved in these pathways likely influences the development of obesity.

Uncoupling proteins (UCPs) belong to the family of mitochondrial transporter proteins that are important in energy homeostasis. UCPs have become prominent in the fields of thermogenesis, obesity, diabetes, and free-radical biology and have been considered candidate genes for obesity and insulin resistance [6]. Among the five subtypes of UCPs, UCP3 is a member of the mitochondrial transporter super family and is expressed predominantly in skeletal muscles $[7,8]$. UCP3 mediates energy expenditure via mitochondrial proton leak and lipid metabolism [9-12] and is involved in fatty acid translocation [13]. Reduction in the function or expression of UCP3 likely decreases energy expenditure or increases fat storage of energy [14]. UCP3 is negatively correlated with body mass index (BMI) [15], suggesting a potential link between UCP3 and obesity, potentially by the proposed roles of UCP3 in facilitating fatty acid oxidation [16] and preventing triglyceride accumulation [17]. Therefore, UCP3 likely modulates body weight, but further investigation is needed to confirm this.

Vitamin D (VD) is a fat-soluble vitamin that is either synthesized in the skin after exposure to solar UVB radiation or obtained from the diet. VD regulates both bone metabolism and calcium-phosphorus homeostasis [18]. In humans, vitamin D3 (VD3, cholecalciferol) is transformed to 1, 25-dihydroxyvitamin $\mathrm{D}_{3}\left(1,25(\mathrm{OH})_{2} \mathrm{D}_{3}\right)$ (calcitriol), the most active form [19]. Calcitriol functions are primarily activated by its nuclear receptor, vitamin D receptor (VDR), which recruits its preferred dimerization partner, retinoid $\mathrm{X}$ receptor (RXR), to form a heterodimer. This complex acts as a ligand-dependent transcription factor that combines with vitamin $\mathrm{D}$ response elements (VDRE) in the promoter regions of target genes $[20,21]$.

Recent epidemiological investigations found that low serum calcitriol levels are associated with a higher BMI and greater body fat $[22,23]$. Additionally, elevated dietary VD intake and serum 25(OH)D levels are associated with reduced omental adipocyte size and lower visceral adiposity, which have important clinical implications [24]. Increasing evidence suggests that VD3 supplementation limits weight gain induced by high-fat diets due to increased lipid oxidation [25]. Administration of calcitriol regulates peroxisome proliferator-activated receptor $\alpha$ (PPAR $\alpha)$, which prevents high-fat diets-induced body weight gain by inhibiting lipogenesis [26]. Reports regarding VD3 and obesity have been contradictory; for example, VDR knock-out mice are resistant to high-fat diets-induced weight gain [27] and show a slower growth rate and accumulate less fat mass [28]. Therefore, further research on the effect of VD3/VDR on obesity is needed. To investigate the influence of VD3/VDR on body weight and lipid, we investigated the energy metabolism in obese mice consuming a high-fat diet and a possible consensus sequences in the UCP3 promoter for VDR.

\section{Methods}

\section{Animal and treatment}

Eight-week-old male C57BL/6 J mice (Japan SLC, Shizuoka, Japan) were acclimated in the animal facility under a 12 -h light/dark cycle prior to the experiment. For 9 weeks, the mice were fed a control normal-fat diet (group NFD: $10 \mathrm{kcal} \%$ fat (lard)), (D12450B, Research Diets Inc, NJ, US) or a high-fat diet (groups HFD and HFVD: $45 \mathrm{kcal} \%$ fat (lard)), (D12451, Research Diets Inc). We used HFD feeding as previously described [25]. Both NFD and HFD mice were treated with vehicle $(1 \%$ ethanol, $9 \%$ pure water, $90 \%$ corn oil). HFVD mice were treated with $50 \mu \mathrm{g} / \mathrm{kg}$ body wt/d cholecalciferol (VD3) (C0314, TCI, Tokyo Japan) administered by gavage daily. We determined the dose of VD3 to feed as previously described [18]. Body weight was measured every day and food intake was calculated per cage. Mice were fasted $24 \mathrm{~h}$ before sacrificing, at which point perfused normal saline from the left ventricle of the heart, blood, liver, mesenteric adipose, kidney adipose, epididymis adipose, and thigh rectus femoris muscle were collected and analyzed.

\section{Blood serum analysis}

Mouse blood samples were placed on ice for $1 \mathrm{~h}$ and then centrifuged at $3500 \times \mathrm{g}$ for $90 \mathrm{~s}$. The blood serum was collected and total cholesterol (T-CHO), low density lipoprotein-cholesterol (LDL-C), high density lipoproteincholesterol (HDL-C), and triglyceride (TG) were measured using LabAssay ${ }^{\text {mm }}$ Cholesterol (294-65801, Wako Pure Chemical Industries, Ltd, Japan), LabAssay ${ }^{\text {min }}$ Glucose (29865701), LabAssay ${ }^{\mathrm{ma}}$ Triglyceride (290-63701), according to manufacturer's instructions.

\section{Tissue sample RNA extraction for quantitative real-time PCR and PCR agarose electrophoresis}

Total RNA was extracted from homogenized $\sim 1 \mathrm{~mm}$ sliced tissue samples using the RiboZol RNA extraction reagents (N580, AMRESCO, US). cDNA was synthesized using iScript Reverse Transcription Supermix (170-8841, BIO-RAD, US) and the following conditions: $25^{\circ} \mathrm{C}$ for 5 min, $42{ }^{\circ} \mathrm{C}$ for $30 \mathrm{~min}, 85^{\circ} \mathrm{C}$ for $5 \mathrm{~min}, 4{ }^{\circ} \mathrm{C}$ until use. Real-time qPCR was conducted using SsoAdvanced Universal SYBR Green Supermix (172-5271,BIO-RAD). The cycle conditions were as follows: $95{ }^{\circ} \mathrm{C}$ for $1 \mathrm{~min}$ 
followed by 39 cycles of $95{ }^{\circ} \mathrm{C}$ for $5 \mathrm{~s}$ and $59.5{ }^{\circ} \mathrm{C}$ for $10 \mathrm{~s}$. The level of UCP3 mRNA was evaluated from thigh rectus femoralis muscle samples and the housekeeping gene GAPDH was used as an internal control. Expression of liver $\mathrm{X}$ receptors (LXRs), farnesoid $\mathrm{X}$ receptor (FXR), peroxisome proliferator-activated receptor (PPAR), and related genes were measured in the same methods.

To amplify VDR and $\beta$-actin, PCR was performed as follows: 30 cycles of $98{ }^{\circ} \mathrm{C} 10 \mathrm{~s}, 55{ }^{\circ} \mathrm{C} 30 \mathrm{~s}$, and $72{ }^{\circ} \mathrm{C}$ $15 \mathrm{~s}$. VDR and $\beta$-actin PCR products (188 bp and $192 \mathrm{bp}$, respectively) were confirmed by $2 \%$ agarose gel electrophoresis, ethidium bromide staining, and UV light visualization. The primers used are listed in Additional file 1: Table S1.

\section{Cell culture}

Mouse $\mathrm{C} 2 \mathrm{C} 12$ muscle cells (C2C12), rat L6 muscle cells (L6), H-EMC-SS chondrosarcoma cells, and human embryonic kidney cells (HEK293) were purchased from JCRB Cell Bank (National Institute of Biomedical Innovation, Tokyo, Japan). Cells were maintained in Dulbecco's modified Eagle's medium (DMEM) (05919, Nissui Pharmaceutical, Japan) containing 10 \% FBS (SH30910.03, Thermo Scientific, US), $1 \%$ penicillin (168-23191, Wako) and $1 \% \mathrm{~L}(+)$ - Glutamine (074-00522, Wako) at $37{ }^{\circ} \mathrm{C}$ in $5 \%$ $\mathrm{CO} 2$. Cultures were passaged in a subcultivation ratio of 1:3 - 1:4 every two days using $0.25 \%$ w/v Trypsin$1 \mathrm{mmol} / \mathrm{L}$ EDTA-4Na Solution (201-16945, Wako).

\section{Plasmid construction}

The human UCP3 promoter was generously gifted by Dr. Jean A. Boutin (Biotechnologie, Pharmacologie Moléculaire et Cellulaire, Institut de Recherches SERVIER, France). The UCP3 promoter was digested with $\mathrm{XbaI}$ and NcoI and inserted into the pGL4.10-basic vector (Promega Corp., WI) containing the luciferase gene (luc), resulting in a luciferase eukaryotic expression plasmid, which we named UCP3-pro-Luc. The plasmid for mouse UCP3 mRNA interference was generously gifted by Prof. Wolfgang F. Graier (Institute of Molecular Biology \& Biochemistry, Center of Molecular Medicine Medical University of Graz, Austria).

\section{Cell transfection, calcitriol stimulation, and quantitative real-time PCR (qRT-PCR)}

We measured mRNA expression in $\mathrm{C} 2 \mathrm{C} 12$, L6, and $\mathrm{H}-$ EMC-SS untransfected cells or cells transfected with pCMX-VDR, expression plasmid of VDR (pCMX-VDR was provided by K. Umesono and R. M. Evans (Salk Institute, San Diego, CA)). One dish (100 mm) of 5-6 X $10^{5}$ cells were seeded in a 6-well plate and changed to Opti-MEM (31985-070, Gibco, US) until the cells were 70-80 \% confluent. pCMX-VDR (100 ng/well) was transfected using Lipofectamine 2000 DNA transfection reagent (11668-019, Invitrogen, Life Technologies, US) for $5 \mathrm{~h}$ then the medium was changed to DMEM. Calcitriol $(50 \mathrm{nM})$ was added and cells were incubated for $24 \mathrm{~h}$. For mRNA analysis, total RNA was isolated using the RiboZol RNA extraction reagents. cDNA synthesis and real time PCR were conducted as described above. UCP3 mRNA expression was measured in C2C12, L6, and H-EMC-SS cells. The housekeeping gene GAPDH was used as an internal control.

Calcium phosphate cell transfection, calcitriol stimulation, and dual luciferase assay

The reporter plasmid (UCP3-pro-luc, $100 \mathrm{ng} / \mathrm{mL}$ ), expression plasmid of VDR (pCMX-VDR, $50 \mathrm{ng} / \mathrm{mL}$ ), and internal control plasmid (pGL $4.70 \quad 10 \mathrm{ng} / \mathrm{mL}$ ) were transfected into HEK 293, C2C12, and H-EMC-SS cells using $0.01 \mathrm{M}$ Tris- $\mathrm{HCl}, 2.5 \mathrm{M} \mathrm{CaCl} 2$, and $2 \times \mathrm{HBS}$. About $5 \mathrm{~h}$ after transfection, the media was changed to DMEM. A gradient of calcitriol $(0.1-100 \mathrm{nM})$ was added and the cells were stimulated for $24 \mathrm{~h}$. The cells were harvested using 1× Passive Lysis Buffer (E194A, Promega, WI) and measured by the Dual Luciferase Reporter Assay System (E1960, Promega, Corp. WI) according to the manufacturer's instructions.

\section{Candidate VDRE sequence search using the UCP3 promoter deletion model}

PSORTII (PSORTII computer software provided by the Human Genome Center, Institute for Medical Science, Tokyo University, Japan) was used to detect putative VDREs. All settings used were default settings. Of the detected sequences, those with significant similarities or identical to the mouse osteopontin were selected [29]. Then we generated five deletion constructs containing the candidate VDREs to screen for functional regions (Fig. 5a). Next we subcloned ten putative VDREs from the 5'-flanking region of UCP3 and prepared ten reporter constructs, each containing a VRDE candidate as previously prescribed [30]. In briefly, the reporter plasmid VDRE-tk-luc contains one copy of the mouse osteopontin VDRE upstream of a $151 \mathrm{bp}$ truncated thymidine kinase promoter, inserted between the SacI and HindIII sites of the pGL 4.10-basic vector and was used as the positive control. Each candidate was inserted into VDRE-tk-luc substituting for the mouse osteopotin VDRE. The candidates consisted of -2200: designates as (1), -2043: (2), -1867: (3), -1561: (4), -634: (5), -595: (6), - 80 : (7), -1: (8), +162: (9), and +314 bp :(10) of the UCP3 promoter. The primers used for reporter plasmid construction are listed in Additional file 1: Table S2. The relative luciferase activity of each reporter was compared with the positive control using the protocol described above. 


\section{Statistical analysis}

The results are shown as the mean $\pm \mathrm{SD}$. The significance of differences was determined by one-way ANOVA and post hoc Bonferroni/Tukey test for multiple comparisons using SPSS 17.0 software. A p-value of $P<0.05$ was considered statistically significance.

\section{Results}

VD3 supplementation protected against high fat dietinduced obesity VD3 limited the body weight gain of HFD mice

High-fat diet feeding mice treated with cholecalciferol (HFVD) gained less weight compared to the HFD group (Additional file 2: Figure S1). After the fifth week, the difference in weight gain between groups was significant (Fig. 1a, $P<0.05$ ). The weight gain of HFD mice was $206.7 \%$ of that of the NFD group. On the other hand, the weight gain of HFVD mice was $51.8 \%$ compared to the NFD group (Fig. 1b, $P<0.01$ ). Food consumption was not different between each group (Fig. 1c).

\section{VD3 decreased fat mass in HFD mice}

We measured the tissue weight of epididymis adipose, kidney adipose, and mesentery adipose to investigate fat distribution. The weight of epididymis adipose and mesentery adipose was significantly higher in the HFD group compared to the NFD group by 142.8 and $184.0 \%$, respectively $(P<0.01)$. Treatment with cholecalciferol increased tissue weight by 44.4 and $48.4 \%$, respectively $(P<0.01)$ compared to NFD mice (Fig. 1d).

\section{VD3 had no effects on altering serum lipid}

Glucose and serum lipids include TC, LDL-C, HDL-C, and TG. The serum levels of the HFD and the HFVD groups had no significant change when compared with the NFD group (data not shown).

\section{VD3 elevated the mRNA expression of UCP3 in the thigh rectus femoris muscle}

To explore the potential mechanism of the reducing body weight effects of cholecalciferol, we examined the mRNA expression of various target genes that were reported to be involved in lipid, glucose and energy metabolisms, paying special attention to UCP genes. We measured UCP3 mRNA levels in the thigh muscle using qRT-PCR. The expression of UCP3 mRNA in the thigh muscle increased in the cholecalciferol treated HFVD group compared with the untreated HFD group $(P<0.01$, Fig. $2 \mathrm{a})$. We also examined that VDR was present in white adipose tissue, liver, and muscle by PCR agarose electrophoresis in every group (Additional file 3: Figure S2). These results suggest cholecalciferol

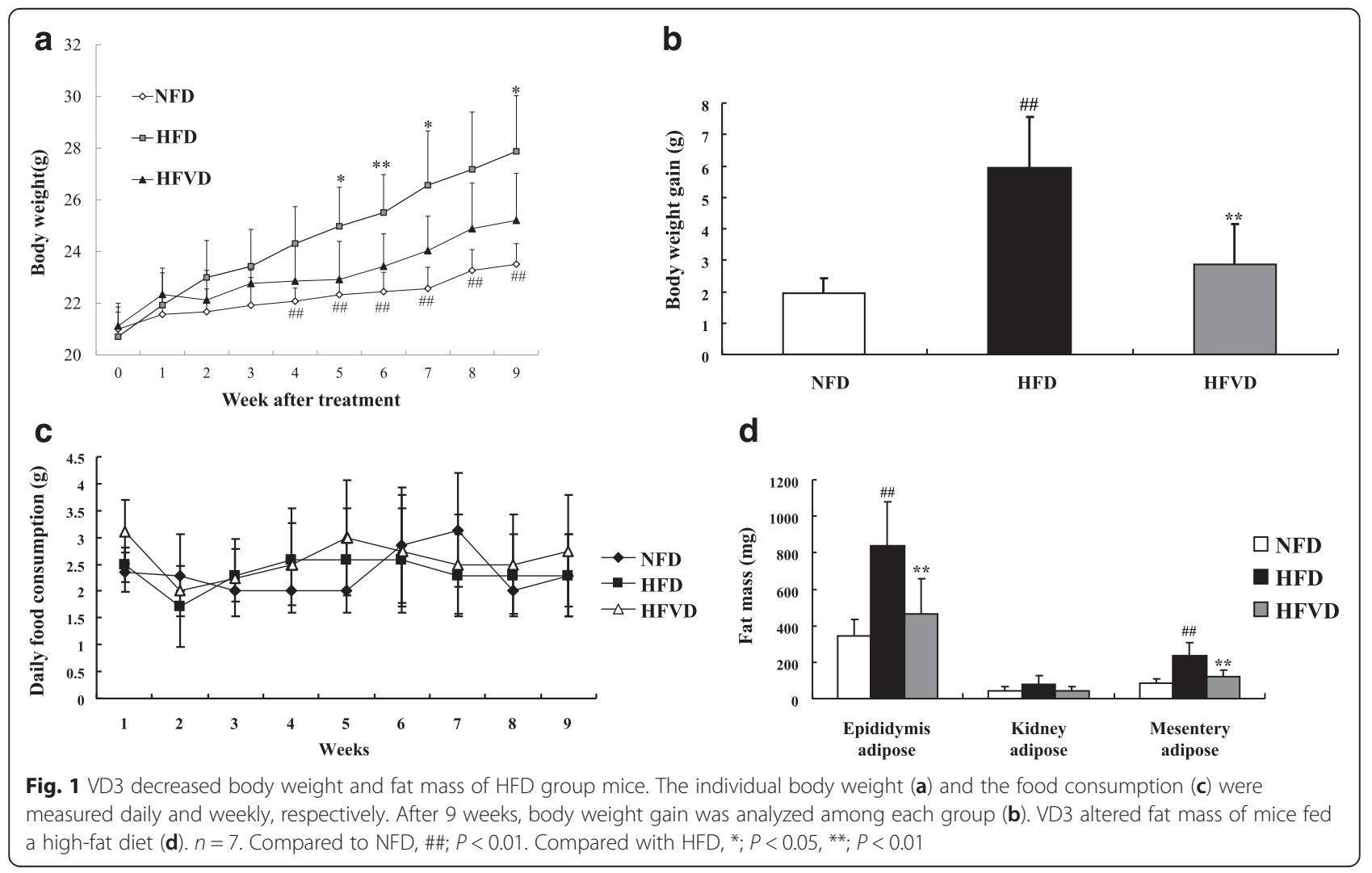


decreases body weight and may alter energy metabolism by involving UCP3 (Fig. 2b). We also observed the expression level of mRNA of UCP1 in the brown and white adipose tissues. Those were not elevated by administration of VD3 (Additional file 4: Figure S3).

\section{Relative luciferase activities of UCP3-pro-luc were dose dependent on calcitriol in three muscle cell lines}

To determine the effects of calcitriol on relative luciferase activities of UCP3-pro-luc, we used the Dual Luciferase Assay in $\mathrm{C} 2 \mathrm{C} 12$ cells (Fig. 3a), L6 (Fig. 3b), and H-EMC-SS (Fig. 3c). Compared with the vehicle control, luciferase activity was significantly increased in a dose dependent manner as concentrations of calcitriol $(0.1-100 \mathrm{nM})$ increased. The UCP3-pro-luc promoter activity in H-EMC-SS cells was enhanced by $1 \mathrm{nM}$ $(P<0.05), 10 \mathrm{nM}(P<0.01)$, and $100 \mathrm{nM}(P<0.01)$ calcitriol. Similar effects were observed in both $\mathrm{L} 6$ and $\mathrm{C} 2 \mathrm{C} 12$ cells by $100 \mathrm{nM}$ calcitriol $(P<0.05)$.

\section{UCP and nuclear receptor genes were affected by calcitriol especially combined with VDR}

To detect the effects of VD3 on energy metabolism, we analyzed the expression of UCP3 mRNA in $\mathrm{C} 2 \mathrm{C} 12$ (Fig. 4a), L6 (Fig. 4b), and H-EMC-SS (Fig. 4c) both untransfected and transfected with VDR. In untransfected VDR C2C12 cells, UCP3 mRNA increased in the presence of $50 \mathrm{nM}$ calcitriol $(P<0.05)$. In VDR transfected cells, the same patterns were amplified $(P<0.01)$. The siRNAs against mouse UCP3 diminished expression of the respective transcript (Fig. 4a).

Identification of a functional consensus sequence of VDR binding sites in the UCP3 promoter

All truncated reporter constructs had at least some promoter activity although the actual strength was dependent on the length of UCP3 promoter (Fig. 5a). Above all, abrogation between -861 and -476 on the UCP3 promoter significantly decreased the transcriptional activity to 54.7 $\pm 2.4 \%$ of that $-861 \mathrm{UCP} 3$-pro-Luc (Fig. $5 \mathrm{a}$ ). Therefore, the results indicate that there are multiple functional VDREs in the UCP3 promoter. We examined luciferase activity of our generated reporter constructs containing putative VDREs. The magnitude of activation was dependent on sequence similarity to the osteopontin VDRE (AGGTCAcgaAGGTCA) (Fig. 5b, Additional file 1: Table S2 and S4). These results suggest that the functional VDREs are located at $-2200,-1561,-634$, and +314 bp of the proximal region of the UCP3 promoter.

\section{Discussion}

In this study, we determined the effects of VD3 on obesity in mice fed high-fat diets. Body weight, weight gain, and white adipose tissue decreased in mice treated with VD3. Some metabolism genes, including UCP3, had altered gene expression in VD3 treated mice, suggesting variation in mitochondrion function might be involved. In addition, we identified the functional consensus sequence of calcitriol/VDR in the UCP3 promoter.

Some researchers have shown that liganded VDR represses PPARy expression via inhibition of C/EBP $\beta$ expression and inhibits adipogenesis [31,32]. Other studies suggest that the anti-adipogenic effect of calcitriolsuppressing transcription factor PPAR $\gamma$ is mediated by WNT10B and nuclear $\beta$-catenin expression levels in 3 T3-L1 preadipocytes [33]. To examine if VD3 decreases obesity, we fed C57BL/6 mice a high-fat diet for 9 weeks to mimic the pathogenesis of obesity, which results in increased body weight gain and other metabolic disturbances by affecting food intake and peripheral metabolism [34]. Based on the previously described association between obesity and VD3, we investigated the role of VD3

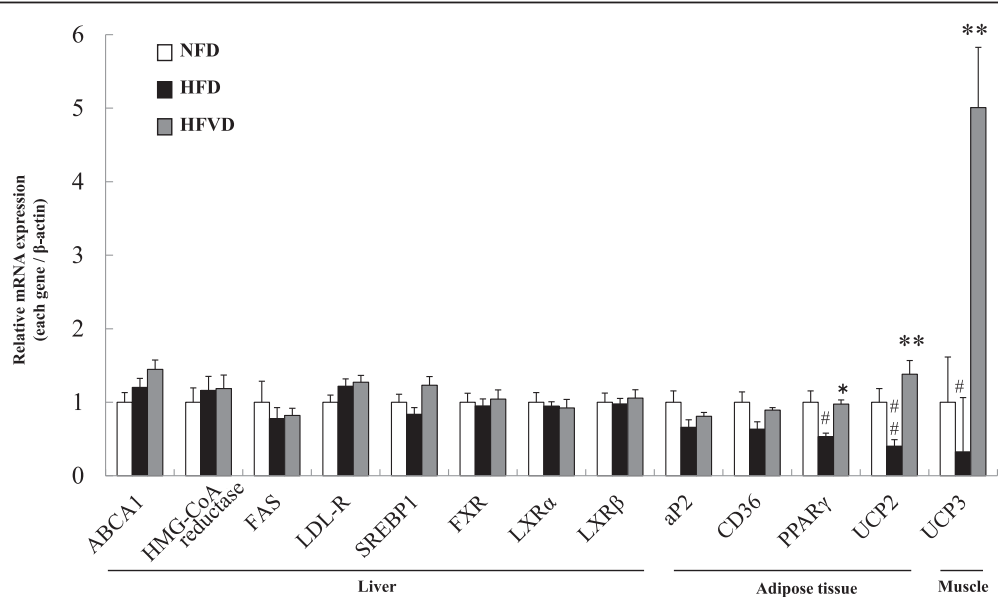

Fig. 2 VD3 increased UCP3 mRNA expression in muscles. The effects of VD3 on UCP3 mRNA expression in the thigh rectus femoris muscle of mice fed a high-fat diet. $n=5$. Compared with NFD, ${ }^{* *} ; P<0.01$ 


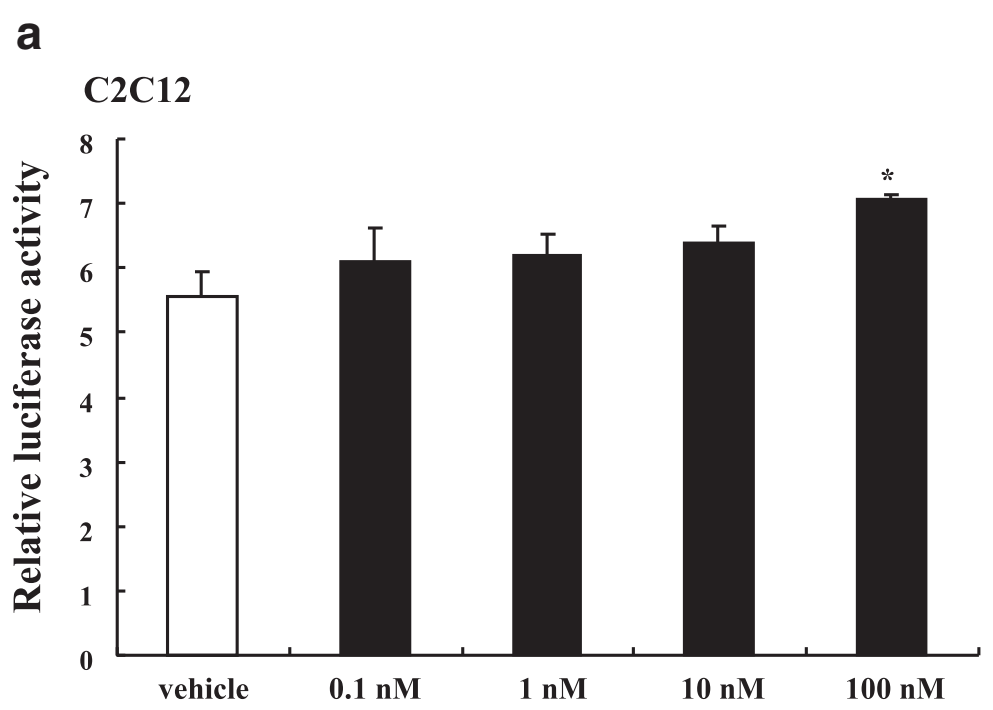

b

L6

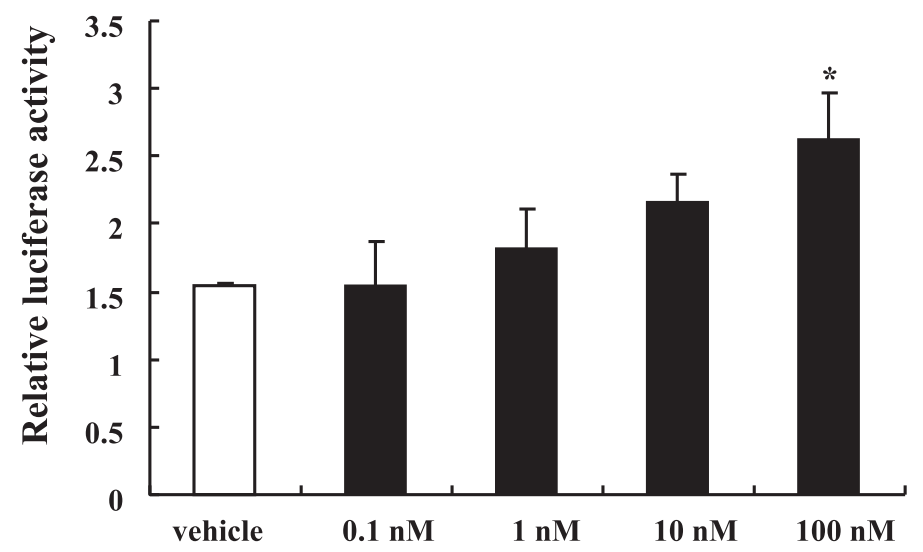

C

H-EMC-SS

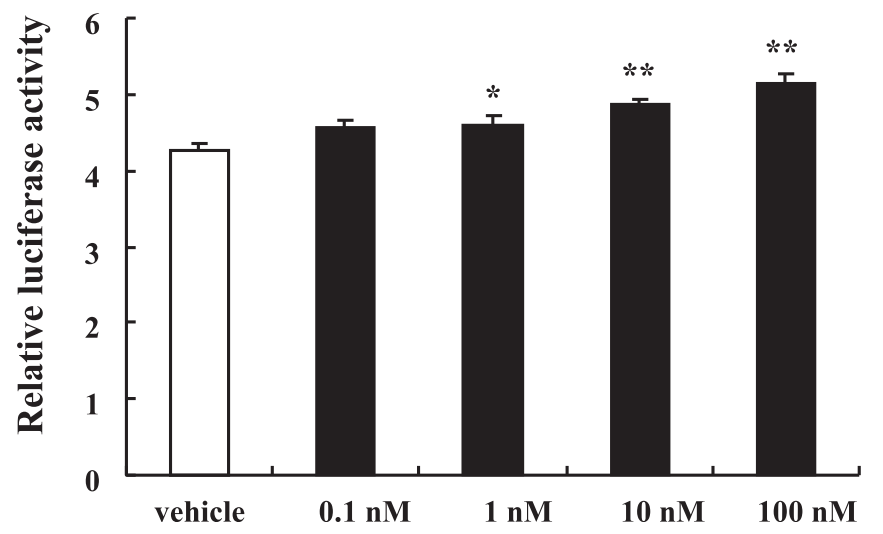

Fig. 3 Calcitriol enhanced relative luciferase activity in a dose dependent manner. UCP3-pro-luc was transfected into C2C12 cells (a), L6 cells (b), and H-EMC-SS cells (c). Relative luciferase activity was analyzed by Dual Luciferase Assay after stimulation with calcitriol. $n=3$, compared with vehicle, ${ }^{*}: P<0.05$; $^{* *}: P<0.01$ 

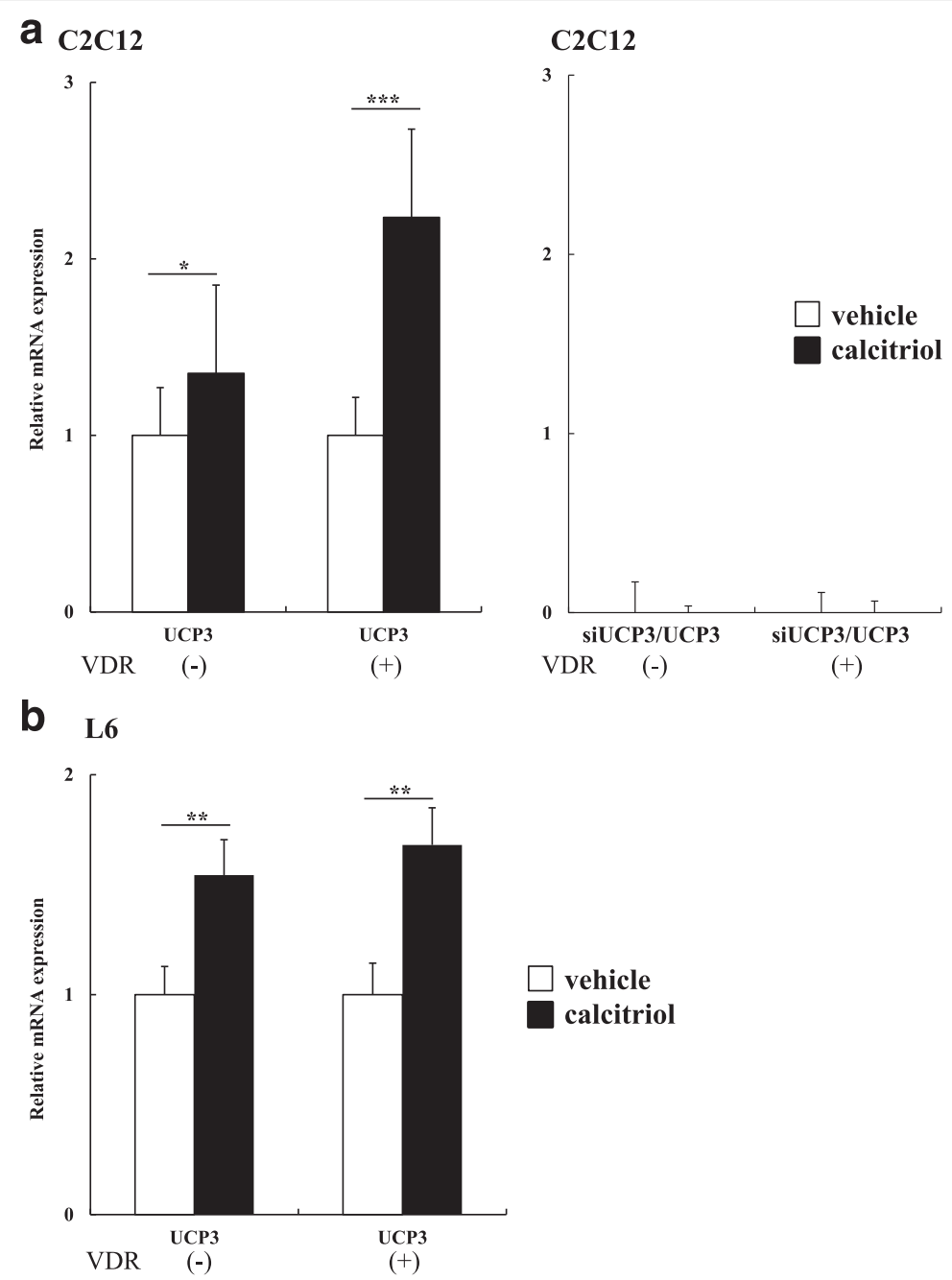

vehicle

calcitriol

\section{H-EMC-SS}

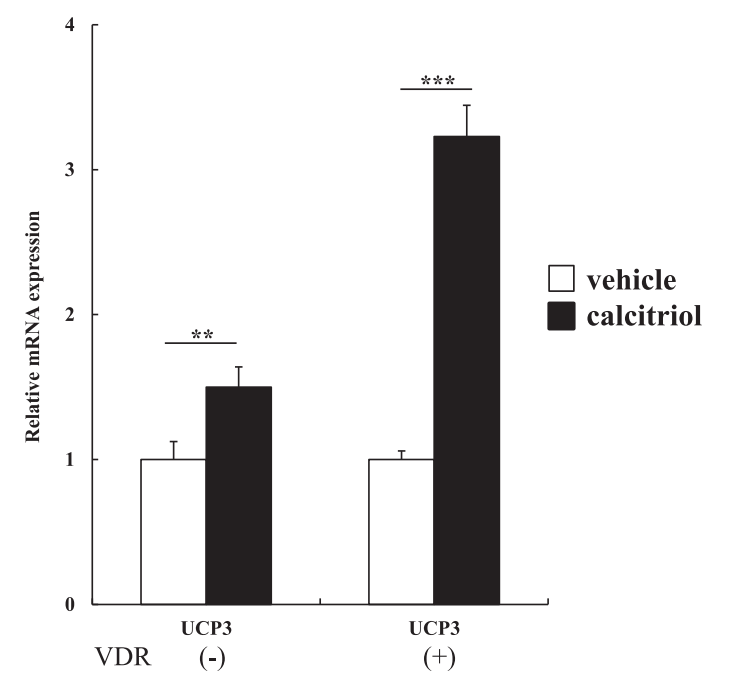

Fig. 4 (See legend on next page.) 
(See figure on previous page.)

Fig. 4 Calcitriol increased UCP3 mRNA expression in muscle cells. Relative mRNA expression was detected in C2C12 cells (a), L6 cells (b), and H-EMCSS cells (c) using qRT-PCR. To investigate the role of calcitriol and VDR on UCP3 mRNA expression, we transfected with a control plasmid ((-) mock) or VDR expression plasmid ((+) pCMX-VDR). We also performed loss-of-function experiments using selective siRNA against UCP3 (a). Compared with nontransfected controls, siRNAs against UCP3 strongly reduced the expression of the UCP3. $n=3$. Compared with vehicle, ${ }^{*} ; P<0.05,{ }^{* *} ; P<0.01$. ***; $P<0.005$

on modulating body weight. Body weight significantly increased after 4 weeks for the HFD group while treatment with VD3 (HFVD) resulted in decreased body weight beginning the fifth week compared to the HFD group (Fig. 1a). Similar to changes in body weight, VD3 supplemented mice gained less weight than HFD mice in spite of that all mice have the almost same original body weight. However, daily food consumption was almost constant, implying appetite was not affected between groups and that differences in weight gain cannot be attributed to differences in calorie intake (Fig. 1c). We measured the mass of visceral adipose tissue and observed changes in the weight of epididymis adipose and mesentery adipose in HFD mice in accordance with changes in body weight (Fig. 1d). We speculate that decreased adipose tissue weight in VD3 supplemented mice is due to the inhibition of adipogenesis.

Levels of blood lipid total-cholesterol, LDL-cholesterol, HDL-cholesterol, triglyceride, and glucose were comparable between treatments, suggesting the variation in body weight and adipose tissue did not affect serum lipid levels (data not shown). To investigate the mechanism of VD3associated inhibition of weight gain, we measured mRNA levels by qRT-PCR in muscle and adipose samples. The results show weight loss by VD3 supplementation may occur by UCP3 in thigh rectus femoris muscle, suggesting VD3 may influence energy metabolism and thereby alter body weight. Recent findings also highlight a new role for calcitriol and its receptor VDR in adipose tissue energy homeostasis [35], especially in regulating UCP expression [28]. We identified the existence of VDR by PCR gel electrophoresis, suggesting that VD3 modulates body weight by interacting with its receptor VDR.

To explore the role of VD3 in the modulation of body weight, we performed in vitro experiments using $\mathrm{C} 2 \mathrm{C} 12$, L6, H-EMC-SS cells to observe the expression of genes involved in energy and lipid metabolism, including UCP3. These three cell types represent both different species and different muscle cell types. We employed $\mathrm{H}-$ EMC-SS cells, as substitutes for myocyte or myoblast cell lines to examine VD3 action on human derived cell line. We demonstrated that calcitriol upregulates the expression of UCP3 in all cell types, with even higher expression in pCMX-VDR transfected cells. Those results underline that UCP3 gene in muscle cell lines are positively regulated by VDR-mediated gene transcription. Furthermore, we verified the presence of VDR in these cells by examining the expression of VDR (Additional file 5: Figure S4). Expression levels of VDR mRNA were varied depending on the cell lines, though the level of them were less than that of the skeletal muscle. To verify the effect of calcitriol on relative luciferase activities, we used the Dual Luciferase Assay in UCP3-pro-luc transfected cells. The relative luciferase activities increased in response to calcitriol in a dose dependent manner in all cell lines. These data indicate that treatment of muscle cells with calcitriol increases the promoter activity in the presence of UCP3. Therefore, calcitriol enhances the expression of UCP3 in muscle cell lines via binding to VDR.

UCP and respiration uncoupling are implicated in numerous physiological and pathological processes, including adaptive thermogenesis [36], regulation of fatty acid oxidation [37], and body weight regulation [38]. UCP3 protects against lipid-induced mitochondrial damage by facilitating the export of fatty acids that cannot be oxidized from the mitochondrial matrix [39]. The previous report revealed that the moderate overexpression of UCP3 led to an increase in mitochondrial oxygen consumption and reduced oxidative phosphorylation efficiency in skeletal muscle fibers [40]. Overexpression of UCP3 mRNA in mouse skeletal muscle reduces dietinduced obesity, suggesting that UCP3 has therapeutic potential in the treatment of obesity [38]. UCP3 is thought to regulate mitochondrial fatty acid oxidation. For example, gastrocnemius muscle mitochondria isolated from $\mathrm{UCP}^{+/+}$mice can better oxidize fatty acids and result in lower fatty acid levels than those of UCP3 +/- and $\mathrm{UCP}^{-/-}$mice [41]. UCP3 protects against body weight and fat gain [42] and prevents accumulation of triglycerides in both adipose tissues and muscles [43] during high-fat feeding. Higher levels of fat are stored in mice lacking UCP3 that are fed high-fat diets [17]. In skeletal muscles, reduced mitochondrial uncoupling impairs mitochondrial fatty acid oxidation, leading to fatty acid and/or metabolite accumulation and increased oxidative stress, which results in obesity [44, 45].

We showed a significant increase in UCP3 mRNA expression by VD3 in thigh rectus femoris muscles. Additionally, UCP3 mRNA expression increased in both untransfected and pCMX-VDR-transfected C2C12, L6, and H-EMC-SS cells. The relative luciferase activity increased in a calcitriol-dose-dependent manner in three different muscle cells transfected with the UCP3-pro-luc 


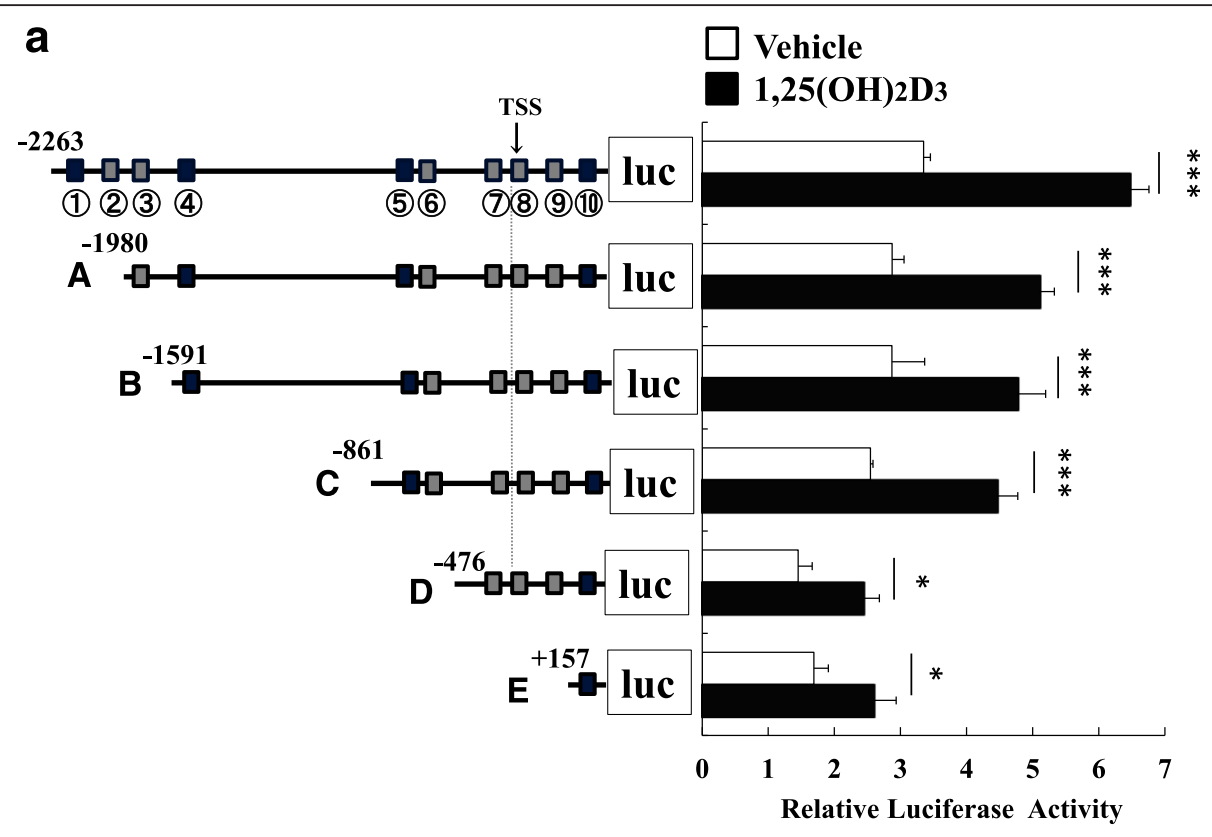

b

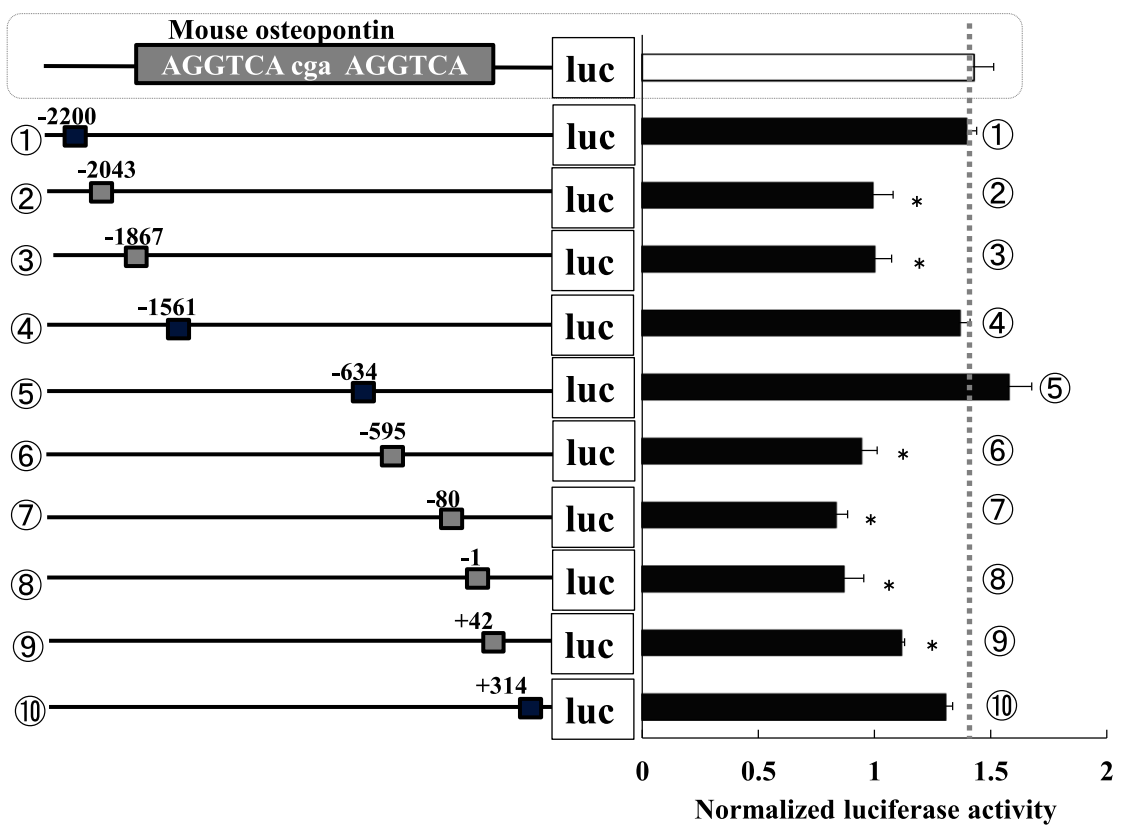

Fig. 5 VD3 responsiveness of candidate VDRE upon transient transfection. The schematic structure of the proximal region of the human UCP3 promoter is shown; nucleotides are numbered relative to the transcriptional start site (TSS). The number below the top line denotes the position of the putative VDRE in the UCP3 promoter as follows; -2200; (1), -2043; (2), -1867; (3), -1561; (4), -634; (5, -595; (6, -80; (7), -1; (8), +162; (9), and +314; (1). Each truncated UCP3-pro-luc reporter construct and CMX-hVDR were co-transfected into HEK-293 cells and relative luciferase activity was compared. a Error bars represent SD from at least three experiments. $n=3$. Compared with the control, ${ }^{*} ; P<0.05,{ }^{* * *} ; P<0.005$. Solid boxes represent putative VDRE with high sequence similarity to the positive control (more than $80 \%$ ). Shadow boxes represent those with medium similarity (more than $70 \%$ ), open boxes represent those with relatively low similarity (more than $60 \%$ ) to the positive control. b As a positive control for VD3 responsiveness, we used the mouse osteopotin VDRE (AGGTCAcgaAGGTCA). Relative luciferase activity of each putative VDRE-luc-reporter construct compared to the positive control. Each value is expressed as mean \pm SD from at least three experiments. Both designated nucleotide number relative to the TSS and sequential number is shown of the putative VDREs examined. ${ }^{*} ; P<0.05$ compared to the positive control

vector. Therefore, we speculate that UCP3 facilitates mitochondrial fatty acid oxidation and decreases oxidative stress, thus slowing the progression of obesity.
Finally, we analyzed the UCP3 promoter and VDR for binding site consensus sequences. Deletion analysis of the UCP3 promoter constructs indicated that the VDREs 
are located at $-2200,-1561,-634$, and +314 bp. Particularly, without the No. 5 VDRE sited at -634, the UCP3 promoter activity of transcription decreased dramatically $-45.3 \pm 2.4 \%$ in comparison to its control. So we deduced that the transcriptional activities of calcitriol/VDR primarily depend on its sequence similarity to that of osteopontin, which are known to the most potent VDRE to date. Our results indicate that at least four VDREbinding site consensus sequences on the UCP3 promoter control the transcriptional regulation of UCP3 synergistically depending on the calcitriol/VDR and/or RXR conditions. The liganded VDR binds VDRE on the promoter of target genes and regulates their expression via the formation of heterodimeric complexes with RXR. The VDR also can interact with nuclear receptor, such as PPARs, thyroid hormone receptors, corepressors, coactivators, and many transcriptional factors [30,46]. On the contrary, UCP3 gene promoter harbors several cis-elements essential for expression [47-49]. The relative contribution of those in the regulatory regions to UCP3 gene expression remains to be clarified.

UCPs are a highly useful molecular target for the treatment of obese patients for whom dietary restriction and exercise are difficult. However, because the signal transducers that function downstream of calcitriol/VDR also participate in high calcemia and urinary stones, investigations into the clinical applications of VD3 and/or calcitriol should be conducted cautiously. Therefore, drugs that selectively regulate VDR, which is expressed in myocytes, and intentionally regulate only UCP3 may be used as seeds for further drug development. Such drugs may be beneficial for supplementing weight reduction drugs and for obese patients.

\section{Conclusions}

In summary, the present study demonstrates that the regulation energy metabolism, which was hypothesized to be directly acted on by $1,25(\mathrm{OH})_{2} \mathrm{VD}_{3}$, involves UCP3 via VDR. Furthermore, UCP3 and VDR is expressed widely throughout the skeletal muscle in the whole body. This suggests that circulating $1,25(\mathrm{OH})_{2} \mathrm{VD}_{3}$ are related to the direct effects of local thermogenesis and energy metabolism.

\section{Additional files}

Additional file 1 Table S1. Primer sets used for qRT-PCR. Table S2. Primer sets used for plasmid construction and the VDRE promoter assay. Table S3. VD3 responsiveness of candidate VDRE upon transient transfection. (DOC $55 \mathrm{~kb}$ )

Additional file 2: Figure S1. Comparison of mesenteric fat tissue of representative mouse originated from the breeding stock of each group. Similar phenomena were noticed at the epididymis adipose tissues. (PPTX $281 \mathrm{~kb})$
Additional file 3: Figure S2. VDR mRNA expression was detected in the (1) kidney adipose, (2) mesentery adipose, (3) epididymis adipose, (4) liver and (5) thigh rectus femoralis muscle via PCR gel electrophoresis. The sequences of the primer sets are shown in Additional file 1: Table S1. PCR products of the expected sizes were detected by agarose gel electrophoresis, suggesting that VDR transcripts were present in those tissues. (PPTX $88 \mathrm{~kb}$ )

Additional file 4: Figure S3. UCP1 mRNA expression was detected in the abdominal and epididymal adipose via quantitative real time PCR. The sequences of the primer sets are shown in Additional file 1: Table S1. The expression level of UCP1 in the abdominal adipose tissues of HFDV were less than that of HFD. On the contrary, there was no significant difference between HFD and HFVD in expression level of UCP1 in the epididymal adipose tissue. UCP1 mRNA levels seem to be inconstant, depending on the relative content of browning cell number per volume of the fat. Although HFD treatment had modified the UCP1 mRNA expression levels even in the white adipose tissues, VD3 administration did not have any particular contributions to UCP1 expression to resist diet-induced obesity. (PPTX $47 \mathrm{~kb}$ )

Additional file 5: Figure S4. The presence of VDR transcripts was confirmed by RT-PCR analysis of C2C12 cells, L6 cells, H-EMC-SS cells and the rectus femoris muscle. PCR products of the expected sizes were detected by agarose gel electrophoresis, suggesting that the transcripts were present in each cell line. Beta actin was used as a positive control for PCRs. (PPTX $49 \mathrm{~kb}$ )

\section{Acknowledgements}

The authors are grateful to Dr. Jean A Boutin and Dr. Nagakatsu Harada (University of Tokushima) for kindly providing plasmids. This study was supported by grants from JSPS KAKENHI (No. 16 K19547 to K.F.), the Foundation for Growth Science, the Yamaguchi Endocrine Research Foundation, the Smoking Research Foundation, and Mukogawa Women's University Bioscience Institute.

\section{Authors' contributions}

YF KF, MH, RK and YF of Mukogawa Women's Univ. carried out cell studies and histopathological survey, molecular experiments and prepared the manuscript. MI, TM, MK and TT contributed to give substantial comments on the molecular studies and the manuscript. Initial preparation of the manuscript was carried out by YF and KM with revisions and final approval from all other authors. All authors read and approved the final manuscript.

\section{Competing interests}

The authors declare that they have no competing interests.

\section{Ethics approval and consent to participate}

All experimental animal care and handling were performed in accordance with the recommendations in the Guidelines for the Care and Use of Laboratory Animals at Mukogawa Women's University. The animal experimental protocol was approved by the Institutional Animal Care and Use Committee at Mukogawa Women's University (Approval No: P-15-2014-01-P).

\section{Author details}

${ }^{1}$ Department of Medicine \& Clinical Science, Faculty of Pharmaceutical Sciences, Mukogawa Women's University, Hyogo 663-8179, Japan. ${ }^{2}$ Department of Nephrology and Blood Purification, Institute of Biomedical Research and Innovation, Kobe Medical Frontier Center, Kobe 650-0047, Japan. ${ }^{3}$ Department of Food and Nutrition, Kyoto Women's University, Kyoto 605-8501, Japan. ${ }^{4}$ Clinical Research Institute for Endocrine and Metabolic Diseases, National Hospital Organization Kyoto Medical Center, Kyoto 612-8555, Japan. ${ }^{5}$ School of Chinese Materia Medica, Beijing University of Chinese Medicine, Beijing 100102, China.

Received: 22 February 2016 Accepted: 11 July 2016

Published online: 29 July 2016

\section{References}

1. Kim HG, Jeong HU, Park G, Kim H, Lim Y, Oh MS. Mori folium and Mori Fructus mixture attenuates high-fat diet-induced cognitive deficits in mice. Evid Based Complement Alternat Med. 2015;501:379-418. 
2. Chang JJ, Hsu MJ, Huang HP, Chung DJ, Chang YC, Wang CJ. Mulberry anthocyanins inhibit oleic acid induced lipid accumulation by reduction of lipogenesis and promotion of hepatic lipid clearance. J Agric Food Chem. 2013:61:6069-76.

3. Li L, Wang Z, Zuo Z. Chronic intermittent fasting improves cognitive functions and brain structures in mice. PLoS ONE. 2013;8:e66069.

4. Wong KE, Kong J, Zhang W, Szeto FL, Ye H, Deb DK, Brady MJ, Li YC. Targeted expression of human Vitamin D receptor in adipocytes decreases energy expenditure and induces obesity in mice. J Biol Chem. 2011;286:33804-10.

5. Spiegelman BM, Flier JS. Obesity and the regulation of energy balance. Cell. 2001;104:531-43

6. Jia JJ, Zhang X, Ge CR, Jois M. The polymorphisms of UCP2 and UCP3 genes associated with fat metabolism, obesity and diabetes. Obes Rev. 2009;10:519-26.

7. Vidal-Puiq A, Solanes G, Grujic D, Flier JS, Lowell BB. Ucp3: an uncoupling protein homologue expressed preferentially and abundantly in skeletal muscle and brown adipose tissue. Biochem Biophys Res Commun. 1997;235:79-82

8. Boss O, Samec S, Paoloni-Giacobino A, Rossier C, Dulloo A, Seydoux Muzzin $P$, Giacobino JP. Uncoupling protein-3: a new member of the mitochondrial carrier family with tissue-specific expression. FEBS Lett. 1997;408:39-42.

9. Nabben M, Hoeks J. Mitochondrial uncoupling protein 3 and its role in cardiacand skeletal muscle metabolism. Physiol Behav. 2008:94:259-69.

10. Samec S, Seydoux J, Dulloo AG. Role of UCP homologues in skeleta muscles and brown adipose tissue: mediators of thermogenesis or regulators of lipids as fuel substrate? FASEB J. 1998;12:715-24.

11. Samec S, Seydoux J, Dulloo AG. Post-starvation gene expression of skeletal muscle uncoupling protein 2 and uncoupling protein 3 in response to dietary fat levels and fatty acid composition: a link with insulin resistance. Diabetes. 1999:48:436-41.

12. Clapham JC, Arch JR, Chapman H, Haynes A, Lister C, Moor GB, Piercy V, Carter SA, Lehner I, Smith SA, Beeley LJ, Godden RJ, Herrity N, Skehel M, Changani KK, Hockings PD, Reid DG, Squires SM, Hatcher J, Trail B, Latcham J, Rastan S, Harper AJ, Cadenas S, Buckingham JA, Brand MD, Abuin A. Mice overexpressing human uncoupling protein-3 in skeletal muscle are hyperphagic and lean. Nature. 2000;406:415-8.

13. Bézaire $V$, Seifert EL, Harper ME. Uncoupling protein-3: clues in an ongoing mitochondrial mystery. FASEB J. 2007:21:312-24.

14. Saltzman $E$, Roberts $S B$. The role of energy expenditure in energy regulation: findings from a decade of research. Nutr Rev. 1995;53:209-20.

15. Schrauwen P, Xia J, Bogardus C, Pratley RE, Ravussin E. Skeletal muscle uncoupling protein 3 expression is a determinant of energy expenditure in Pima Indians. Diabetes. 1999:48:146-9.

16. Himms-Hagen J, Harper ME. Physiological role of UCP3 may be export of fatty acids from mitochondria when fatty acid oxidation predominates: an hypothesis. Exp Biol Med. 2001;226:78-84.

17. Costford S, Chaudhry S, Salkhordeh M, Harper ME. Effects of the presence, absence, and overexpression of uncoupling protein-3 on adiposity and fuel metabolism in congenic mice. Am J Physiol Endocrinol Metab. 2006;290:E1304-12

18. He X, Yan J, Zhu X, Wang Q, Pang W, Qi Z, Wang M, Luo E, Parker DM, Cantorna MT, Cui L, Cao Y. Vitamin D inhibits the occurrence of experimental cerebral malaria in mice by suppressing the host inflammatory response. J Immunol. 2004:193:1314-23.

19. Holick MF. The vitamin D epidemic and its health consequences. J Nutr. 2005; 135:2739s-48.

20. Bouillon R, Carmeliet G, Verlinden L, Van Etten E, Verstuyf A, Luderer HF, Lieben L, Mathieu C, Demay M. Vitamin D and human health: lessons from vitamin D receptor null mice. Endocr Rev. 2008;29:726-76.

21. Kato S, Kim M, Yamaoka K, Fujiki R. Mechanisms of transcriptional repression by 1, $25(\mathrm{OH}) 2$ vitamin D. Curr Opin Nephrol Hypertens. 2007;16:297-304

22. Parikh SJ, Edelman M, Uwaifo Gl, Freedman RJ, Semega-Janneh M, Reynolds J, Yanovski JA. The relationship between obesity and serum 1, 25-dihydroxy vitamin D concentrations in healthy adults. J Clin Endocrinol Metab. 2004:89:1196-9.

23. Konradsen S, Ag H, Lindberg F, Hexeberg S, Jorde R. Serum: 1, 25-dihydroxy vitamin D is inversely associated with body mass index. Eur J Nutr. 2008:47:87-91.

24. Caron-Jobin M, Morisset A, Tremblay A, Huot C, Légaré D, Tchernof A. Elevated serum $25(\mathrm{OH}) \mathrm{D}$ concentrations, vitamin $\mathrm{D}$, and calcium intakes are associated with reduced adipocyte size in women. Obesity. 2011;19:1335-41.

25. Marcotorchino J, Tourniaire F, Astier J, Karkeni E, Canault M, Amiot MJ, Bendahan D, Bernard M, Martin JC, Giannesini B, Landrier JF. Vitamin D protects against diet-induced obesity by enhancing fatty acid oxidation. J Nutr Biochem. 2014;25:1077-83.

26. Yin Y, Yu Z, Xia M, Luo X, Lu X, Ling W. Vitamin D attenuates high fat dietinduced hepatic steatosis in rats by modulating lipid metabolism. Eur J Clin Invest. 2012;42:1189-96.

27. Narvaez CJ, Matthews D, Broun E, Chan M, Welsh J. Lean phenotype and resistance to diet-induced obesity in vitamin $D$ receptor knockout mice correlates with induction of uncoupling protein-1 in white adipose tissue. Endocrinology. 2009;150:651-61.

28. Wong KE, Szeto FL, Zhang W, Ye H, Kong J, Zhang Z, Sun XJ, Li YC. Involvement of the vitamin $\mathrm{D}$ receptor in energy metabolism: regulation of uncoupling proteins. Am J Physiol Endocrinol Metab. 2009;296:E820-8.

29. Veenstra TD, Benson LM, Craig TA, Tomlinson AJ, Kumar R, Naylor S Metal mediated sterol receptor-DNA complex association and dissociation determined by electrospray ionization mass spectrometry. Nat Biotechnol. 1998;16:262-6.

30. Tagami $T$, Lutz WH, Kumar R, Jameson JL. The interaction of the vitamin D receptor with nuclear receptor corepressors and coactivators. Biochem Biophys Res Commun. 1998;253:358-63.

31. Blumberg JM, Tzameli I, Astapova I, Lam FS, Flier JS, Hollenberg AN. Complex role of the vitamin $D$ receptor and its ligand in adipogenesis in 3T3-L1 cells. J Biol Chem. 2006;281:11205-13.

32. Kong J, Li YC. Molecular mechanism of 1, 25-dihydroxyvitamin D3 inhibition of adipogenesis in 3T3-L1 cells. Am J Physiol Endocrino Metab. 2006;290:E916-24.

33. Lee H, Bae S, Yoon Y. Anti-adipogenic effects of 1, 25-dihydroxyvitamin D3 are mediated by the maintenance of the wingless-type MMTV integration site/ $\beta$-catenin pathway. Int J Mol Med. 2012;30:1219-24.

34. Jiang T, Wang Z, Proctor G, Moskowitz S, Liebman SE, Rogers T, Lucia MS, Li J, Levi M. Diet-induced obesity in C57BL/6J mice causes increased renal lipid accumulation and glomerulosclerosis via a sterol regulatory elementbinding protein-1c-dependent pathway. J Biol Chem. 2005:280:32317-25.

35. Buettner R, Schölmerich J, Bollheimer LC. High-fat diets: Modeling the metabolic disorders of human obesity in rodents. Obesity. 2007;15:798-808.

36. Ding C, Gao D, Wilding J, Trayhurn P, Bing C. Vitamin D signaling in adipose tissue. Br J Nutr. 2012;108:1915-23.

37. Mozo J, Emre Y, Bouillaud F, Ricquier D, Criscuolo F. Thermoregulation: what role for UCPs in mammals and birds? Biosci Rep. 2005:25:227-49.

38. Jezek P, Garlid KD. Mammalian mitochondrial uncoupling proteins. Int J Biochem Cell Biol. 1998:30:1163-8.

39. Son C, Hosoda K, Ishihara K, Bevilacqua L, Masuzaki H, Fushiki T, Harper ME, Nakao K. Reduction of diet-induced obesity in transgenic mice overexpressing uncoupling protein 3 in skeletal muscle. Diabetologia. 2004;47:47-54.

40. Tiraby C, Tavernier G, Capel F, Mairal A, Crampes F, Rami J, Pujol C, Boutin $J$ A, Langin D. Resistance to high-fat-diet-induced obesity and sexual dimorphism in the metabolic responses of transgenic mice with moderate uncoupling protein 3 overexpression in glycolytic skeletal muscles. Diabetologia. 2007;50:2190-9.

41. Schrauwen $P$, Hesselink MK. The role of uncoupling protein 3 in fatty acid metabolism: protection against lipotoxicity? Proc Nutr Soc. 2004;63: 287-92.

42. Senese R, Valli V, Moreno M, Lombardi A, Busiello RA, Cioffi F, Silvestri E, Goglia F, Lanni A, de Lange P. Uncoupling protein 3 expression levels influence insulin sensitivity, fatty acid oxidation, and related signaling pathways. Pflugers Arch. 2011:461:153-64.

43. Costford SR, Chaudhry SN, Crawford SA, Salkhordeh M, Harper ME. Longterm high-fat feeding induces greater fat storage in mice lacking UCP3. Am J Physiol Endocrinol Metab. 2008;295:E1018-24.

44. Nabben M, Hoeks J, Moonen-Kornips E, van Beurden D, Briedé JJ, Hesselink MK, Glatz JF, Schrauwen P. Significance of uncoupling protein 3 in mitochondrial function upon mid- and long-term dietary high-fat exposure. FEBS Lett. 2011;585:4010-7.

45. Busiello RA, Savarese S, Lombardi A. Mitochondrial uncoupling proteins and energy metabolism. Front Physiol. 2015;6:36

46. Solanes $G$, Pedraza N, Iglesias R, Giralt M, Villarroya F. The human uncoupling protein-3 gene promoter requires $\mathrm{MyoD}$ and is induced by retinoic acid in muscle cells. FASEB J. 2000;14:2141-3.

47. Riquet FB, Rodriguez M, Guigal N, Dromaint S, Naime I, Boutin JA, Galizzi JP. In vivo characterisation of the human UCP3 gene minimal promoter in mice tibialis anterior muscles. Biochem Biophys Res Commun. 2003;311: 583-91. 
48. Acín A, Rodriguez M, Rique H, Canet E, Boutin JA, Galizzi JP. Cloning and characterization of the $5^{\prime}$ flanking region of the human uncoupling protein 3 (UCP3) gene. Biochem Biophys Res Commun. 1999;258(2):278-83.

49. Hoffmann C, Zimmermann A, Hinney A, Volckmar AL, Jarrett HW,

Fromme T, Klingenspor M. A novel SP1/SP3 dependent intronic enhancer governing transcription of the UCP3 gene in brown adipocytes. PLoS ONE. 2013;31:e83426.

Submit your next manuscript to BioMed Central and we will help you at every step:

- We accept pre-submission inquiries

- Our selector tool helps you to find the most relevant journal

- We provide round the clock customer support

- Convenient online submission

- Thorough peer review

- Inclusion in PubMed and all major indexing services

- Maximum visibility for your research

Submit your manuscript at www.biomedcentral.com/submit
Biomed Central 